Pediat. Res. 2: 209-214 (1968)

Agammaglobulinemia

blast transformation

Bruton's disease
C. albicans antigen delayed hypersensitivity lymphocytes

\title{
Lymphocytes in Agammaglobulinemia: In Vitro Response to a Specific Antigen
}

\author{
S.P. GoтoFF ${ }^{[32]}$ \\ Department of Pediatrics, University of Illinois College of Medicine, Chicago, Illinois (USA)
}

\begin{abstract}
Extract
Peripheral blood leukocytes from eleven normal individuals and five boys with Bruton-type agammaglobulinemia were cultured in vitro with Candida albicans antigen. The lymphocyte response in vitro was measured by morphologic transformation into blast cells and by incorporation of tritiated thymidine into DNA. Delayed hypersensitivity was measured by the standard skin test, and circulating antibody titers were estimated by agglutination of heat-killed candida.

A response to candida antigen was demonstrated in cultures of lymphocytes taken from six normal individuals (table I) and from four patients with agammaglobulinemia (table II). The in vitro lymphocyte response correlated with the results of skin tests but not with titers of circulating antibody.

The results with agammaglobulinemic lymphocytes support the view that the in vitro lymphocyte response is a correlate of delayed hypersensitivity.
\end{abstract}

\section{Speculation}

Both humoral antibody formation and delayed hypersensitivity reactions originate in lymphoid tissues. From these tissues, small lymphocytes circulate to peripheral blood. Investigations of peripheral blood lymphocytes from patients with Bruton-type agammaglobulinemia are of interest because these patients have normal delayed hypersensitivity reactions despite an inability to synthesize more than trace amounts of circulating antibody. As a result, these patients may be considered a source of lymphocytes with immunologic capacity limited almost entirely to delayed hypersensitivity.

\section{Introduction}

Peripheral blood lymphocytes from previously sensitized normal donors will respond to the appropriate specific antigen in vitro by transformation into blast cells and by the incorporation of precursors into nucleic acids [14, 21]. Previous studies of lymphocytes from patients with agammaglobulinemia have demonstrated a normal response to the nonspecific mitogens, phyto-

14 Pediat. Res., Vol. 2, No. 3 (1968) hemagglutinin (PHA) and streptolysin S $[9,12]$; however, attempts to induce an in vitro response with specific antigens have yielded conflicting results $[6,9,12]$. The present study demonstrates that lymphocytes from patients with Bruton-type agammaglobulinemia respond to a specific antigen in vitro and that this response correlates with the presence of delayed hypersensitivity reactivity in vivo. 
Material and Methods

Five boys between the ages of 5 and 17 years with congenital X-linked agammaglobulinemia comprised the study group. Family histories of male siblings or maternal uncles revealed recurrent infections and early deaths from infections which were consistent with $\mathrm{X}$ linked inheritance. Immunoglobulins $\mathrm{G}, \mathrm{A}$ and $\mathrm{M}$ were measured by radial diffusion in agar with monospecific rabbit antisera [17]. Except for patient P. G., the subjects were receiving periodic injections of gamma globulin (100 mg/kg/month) to maintain serum concentrations of $\mathrm{IgG}$ at levels above $1 \mathrm{mg} / \mathrm{ml}$. Normal adults and infants and children recovering from a variety of medical and surgical disorders were used as donors for normal lymphocytes.

Peripheral blood lymphocyte cultures were prepared by a modification of the method of HIRSCHHORN [15]. Heparinized blood was allowed to sediment at $37^{\circ}$ with the addition of $1 \mathrm{ml}$ of plasma gel [25]/10 ml of blood. Leukocytes in autologous plasma were incubated for 6 days at $37^{\circ}$ in Eagle's minimal essential medium (Spinner modification) with $2 \mathrm{mM}$ of 1 -glutamine, $50 \mathrm{U} / \mathrm{ml}$ of penicillin, and $50 \mu \mathrm{g} / \mathrm{ml}$ of streptomycin. The mononuclear cell concentration was $750,000 / \mathrm{ml}$ and the plasma concentration was between 12 and $20 \%$, in a volume of $4 \mathrm{ml}$. A protein extract of Candida albicans $(0.08 \mathrm{ml}$ of $1: 10$ dilution in $50 \%$ glycerin) [26] was added to duplicate or triplicate tubes when the cultures were prepared. Three days prior to harvesting, $2 \mu \mathrm{C}$ of tritiated thymidine (specific activity $2.0 \mathrm{c} / \mathrm{mM}$ ) [27] were added to each culture. On day 6 , the cells were mixed with a pipette and half of the culture was separated for morphologic study. After centrifugation, the cells were suspended in $1 \%$ sodium citrate and fixed in a mixture of ethanol and glacial acetic acid (3:1). Smears were stained with MacNeal's tetrachrome and examined by light microscopy using a $40 \times$ oil objective. Five hundred or, if transformation was noted, one thousand lymphocytes were counted and the percent of transformed cells determined. Lymphocytes with nuclear enlargement, one or more nucleoli, a decreased nuclear : cytoplasmic ratio, and cytoplasmic basophilia with vacuolization were judged to be transformed. Macrophages and cells with altered morphology (nonviable) were excluded from the count.

The remaining half of the culture was prepared for scintillation counting following the method of BAcH and Voynow [2]. After centrifugation, the cell button was frozen and thawed, and the contents were precipitated with cold $5 \%$ trichloracetic acid (TCA). The acid-precipitable material was dissolved in $1 \mathrm{ml}$ of 0.1 $\mathrm{N} \mathrm{NaOH}$, and precipitated again with $4.5 \mathrm{ml}$ of $6.7 \%$ TCA. The precipitate was mixed and washed twice with $5 \%$ TCA, and then dried. The acid-precipitable material was dissolved in $0.5 \mathrm{ml}$ hyamine and transferred to counting vials with $15 \mathrm{ml}$ scintillation fluid (2,5-diphenyloxazole, $4.0 \mathrm{~g} ; 1$,4-bis-2-(4-methyl-5phenyloxazolyl)-benzene, $0.1 \mathrm{~g}$ in one liter of toluene). Each vial was counted three times in a Packard Model 3003 liquid scintillation spectrometer. The counts were averaged, corrected to $100 \%$ efficiency by the channels ratio method, multiplied by two, and expressed as $\mathrm{DPM} / 3 \times 10^{6}$ lymphocytes. Additional cultures were prepared with PHA-M [28] as the additive and harvested at 72 hours.

Tube agglutination with heat-killed Candida albicans was performed as described by Buck and HASENGLEVER [5]. Intradermal skin tests were performed with $0.1 \mathrm{ml}$ of $1: 100$ dilution of Candida albicans antigen [29]. A positive reaction consisted of induration of $1.0 \mathrm{~cm}$ or greater at 24 or 48 hours.

\section{Results}

Concentrations of IgG in serum in the agammaglobulinemic patients receiving gamma globulin were between 1.3 and $1.6 \mathrm{mg} / \mathrm{ml}$. Patient P.C. had $0.26 \mathrm{mg} / \mathrm{ml}$ of IgG in his serum prior to therapy. Levels of IgA and IgM were less than $0.07 \mathrm{mg} / \mathrm{ml}$ and $0.03 \mathrm{mg} / \mathrm{ml}$, respectively, except for those in patient J.M., which were $0.06 \mathrm{mg} / \mathrm{ml}$ of IgM. These values are diagnostic of agammaglobulinemia. Examination of cultures by light microscopy, as well as measurement of tritiated thymidine incorporation into DNA, provided an independent means of assessing the in vitro lymphocyte response. The tetrachrome stain gave good nuclear and cytoplasmic detail which readily differentiated macrophages from blast cells. In the six-day cultures, 20 to $30 \%$ of the cells had distorted morphology, or stained poorly, and were considered nonviable. The percent transformation listed in tables I and II is based on counts of viable lymphocytes.

Five infants with negative skin tests were found (table I). The percent transformation in cultures with candida antigen added ranged between 0 and $1 \%$, a value similar to that of the control cultures without added antigen. There was no increased incorporation of tritiated thymidine in these candida-treated cultures except for one instance (infant, H.D.). In this case there was a two- to three-fold increase in counts. Lymphocyte cultures from these five infants who failed to respond to candida showed over $60 \%$ transformation with PHA, which indicated that the lack of response to candida was specific and reflected neither the presence of a nonspecific lymphocyte abnormality nor a technical problem. 
Table I. In vitro lymphocyte response, skin test results, and agglutinating antibody titers to Candida albicans in donors of normal lymphocytes

\begin{tabular}{|c|c|c|c|c|c|c|c|c|c|}
\hline \multirow[t]{3}{*}{ Name } & \multirow[t]{3}{*}{ Age } & \multirow[t]{3}{*}{ Sex } & \multirow[t]{3}{*}{ Diagnosis } & \multicolumn{4}{|c|}{ In vitro lymphocyte response } & \multirow{3}{*}{$\begin{array}{l}\text { Skin } \\
\text { test }\end{array}$} & \multirow{3}{*}{$\begin{array}{l}\text { Antibody } \\
\text { titer }\end{array}$} \\
\hline & & & & \multicolumn{2}{|c|}{$\%$ transformation $^{1}$} & \multicolumn{2}{|c|}{$\begin{array}{c}\mathrm{H}^{3} \text { thymidine } \\
\text { uptake }^{2}\end{array}$} & & \\
\hline & & & & Control & Candida & Control & Candida & & \\
\hline A.J. & $2 \operatorname{mos}$ & $\mathbf{F}$ & congenital heart & 0.0 & 0.0 & 1,272 & 1,141 & - & $1: 8$ \\
\hline M.B. & $2 \mathrm{mos}$ & $\mathrm{F}$ & well child & 0.8 & 1.0 & 4,206 & 3,884 & - & $1: 4$ \\
\hline H.D. & $5 \mathrm{mos}$ & M & well child & 0.6 & 1.0 & 852 & 2,309 & - & $1: 4$ \\
\hline P.D. & $6 \mathrm{mos}$ & M & pertussis & 0.2 & 0.4 & 1,492 & 1,443 & - & N.T. ${ }^{3}$ \\
\hline R.S. & $6 \operatorname{mos}$ & M & bronchiolitis & 0.0 & 0.0 & 810 & 1,062 & - & $1: 8$ \\
\hline M.S. & $2 \mathrm{mos}$ & F & well child & 0.0 & 3.5 & 1,398 & 9,156 & + & 0 \\
\hline M.H. & $7 \mathrm{yrs}$ & $\mathrm{F}$ & hemangioma & 0.0 & 33.0 & 1,585 & 16,378 & + & $1: 64$ \\
\hline W.V. & 13 yrs & M & nephrotic syndrome & 0.3 & 11.0 & 718 & 24,757 & + & $1: 8$ \\
\hline J.V. & 25 yrs & $\mathbf{F}$ & normal adult & 0.0 & 6.5 & 1,902 & 29,382 & + & $1: 64$ \\
\hline S.G. & 27 yrs & M & normal adult & 0.1 & 11.4 & 1,360 & 4,221 & + & 0 \\
\hline P.G. & $34 \mathrm{yrs}$ & M & normal adult & 0.0 & 48.8 & 2,322 & 52,206 & + & $1: 128$ \\
\hline
\end{tabular}

1 The morphologic changes in control and candida stimulated cultures are expressed as percent blast cell transformation.

${ }^{2} \mathrm{H}^{3}$ thymidine incorporation into DNA is given in DPM $/ 3 \times 10^{6}$ Iymphocytes.

${ }^{3}$ N.T. : Not tested.

Table II. In vitro lymphocyte response, skin test results, and agglutinating antibody titers to Candida albicans in five boys with Bruton-type agammaglobulinemia

\begin{tabular}{|c|c|c|c|c|c|c|c|}
\hline \multirow[t]{3}{*}{ Name } & \multirow{3}{*}{$\begin{array}{l}\text { Age } \\
\text { Years }\end{array}$} & \multicolumn{4}{|c|}{ In vitro lymphocyte response } & \multirow[t]{3}{*}{ Skin test } & \multirow{3}{*}{$\begin{array}{l}\text { Antibody } \\
\text { titer }\end{array}$} \\
\hline & & \multicolumn{2}{|c|}{$\%$ transformation $^{1}$} & \multicolumn{2}{|c|}{$\mathrm{H}^{3}$ thymidine uptake ${ }^{2}$} & & \\
\hline & & Control & Candida & Control & Candida & & \\
\hline P.C. & 5 & 0.0 & 1.2 & 1,313 & 2,285 & - & 0 \\
\hline T.H. & 6 & 0.0 & 18.0 & 649 & 14,139 & + & $1: 8$ \\
\hline B.H. & 13 & 0.0 & 18.7 & 714 & 4,747 & + & $1: 4$ \\
\hline E.D. & 15 & 0.0 & 20.0 & 1,611 & 18,002 & + & $1: 8$ \\
\hline J.M. & 17 & 0.0 & 2.0 & 481 & 3,440 & + & 0 \\
\hline
\end{tabular}

1 The morphologic changes in control and candida stimulated cultures are expressed as percent blast cell transformation.

${ }^{2} \mathrm{H}^{3}$ thymidine incorporation into DNA is given in DPM/3 $\times 10^{6}$ lymphocytes.

Six individuals showed a response to the candida antigen in vitro and in vivo (table I). The percent transformation with the candida antigen ranged from 3.5 to 48.8. An increase of at least a three-fold incorporation of radioactive counts was noted in these responding cells.

The antibody titers did not correlate with the in vitro lymphocyte response or the skin tests. Infants with negative in vitro responses had titers of $1: 4$ and $1: 8$. Two individuals with responsive lymphocytes and positive skin tests had no agglutinating antibodies.

Four of the five boys with Bruton-type agammaglobulinemia had positive skin tests and showed a clear response to candida antigen in vitro (table II). In these cultures, blast cells and those in mitosis (fig. 1) appeared similar to the transformed cells seen in cultures of lymphocytes from normal individuals. Agglutinin titers in serum were quite low. Patient P. C., whose skin test 


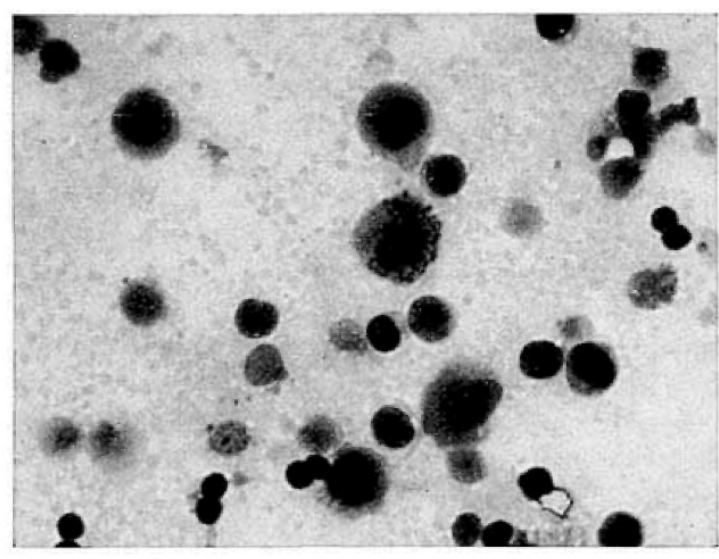

Fig.1. Gandida stimulated lymphocyte culture from T.H., a patient with agammaglobulinemia. Five blast cells, a number of nonresponding small lymphocytes, and one cell in mitosis may be seen.

with the candida antigen was negative, showed $1.2 \%$ transformation but less than a two-fold increase in counts in the candida-stimulated cultures. Untreated with gamma globulin, he had no humoral antibody.

\section{Discussion}

These experiments show clearly that lymphocytes from patients with congenital X-linked Bruton-type agammaglobulinemia may respond to certain specific antigens in vitro as indicated by induction of morphologic changes and incorporation of tritiated thymidine into DNA in cultured cells. While the present results are consistent with the recent preliminary report of COOPERBAND et al. [6], which showed that lymphocytes from patients with agammaglobulinemia had a normal in vitro response to diphtheria and tetanus antigens, and with the work of BACH et al. [3], whose data suggested that at least some patients with Bruton-type agammaglobulinemia can respond to specific antigens, they are at variance with the work of others $[9,12]$. FUDENBERG and HIRSchroron [9] studied two patients with typical X-linked agammaglobulinemia and three patients with the acquired form of the disease. Despite immunization, lymphocytes in culture obtained from these individuals failed to differentiate following addition of diphtheria or tetanus toxoids, typhoid antigen or streptolysin O. Ling and Soothill [16] studied a heterogeneous group of patients with agammaglobulinemia and reported a response by some patients to specific antigens (PPD, streptolysin, diphtheria, E. coli, and smallpox vaccine). Only one child was likely to have had Bruton-type agammaglobulinemia and, in his case, there was no lymphocyte response to PPD and tetanus toxoid. The reason for the failure of earlier investigators to obtain positive results is not clear. The discrepancy may be due to the variation in the types of patients studied or to the degree and type of antigenic stimulation in vivo; however, these investigators $[9,12]$, made their observations using only phase microscopy, which may have obscured minor in vitro responses.

The interpretation of the in vitro lymphocyte response remains controversial. The present study and that of SHANNON et al. [23] have indicated a correlation between the in vitro lymphocyte response to candida antigen and the delayed hypersensitivity skin test. Similar correlations have been obtained using tuberculin [18]. The demonstration of lymphocyte reactivity in vitro in patients with agammaglobulinemia adds further evidence to the concept that the in vitro lymphocyte response can be correlated with the presence of delayed hypersensitivity.

In contrast, the demonstration of gamma globulin synthesis by peripheral blood lymphocytes in vitro $[8$, $22,24]$ indicates that responses in lymphocyte cultures may reflect, in part, activity of the immunoglobulin system. Studies of lymphocytes from patients with penicillin allergy have shown a correlation between the in vitro lymphocyte response and immediate rather than delayed hypersensitivity [7, 10], although the converse has also been reported [10]. In the individual who exhibits an immediate type response, one cannot be certain that delayed type sensitivity is not present, because the estimation of delayed hypersensitivity is currently limited by the relatively insensitive secondary reaction, the skin test. The major supportfor the hypothesis that the in vitro lymphocyte response is a correlate of delayed hypersensitivity has come from studies conducted in guinea pigs $[19,20]$. Furthermore, transplantation immunity is considered to be a delayed hypersensitivity response, and the in vitro lymphocyte response has been shown to reflect differences in histocompatibility [1, 4]. BAck et al. [3] have recently reported that lymphocytes from patients with agammaglobulinemia have a consistent in vitro response to allogeneic cells. Though it is difficult to separate delayed hypersensitivity from humoral antibody responses in man, there are certain diseases of the lymphoid system in which cellular immunity is defective and the capacity for immunoglobulin synthesis may remain intact. Impaired lymphocyte transformation in these disorders $[11,13]$ favors the concept that the in vitro lymphocyte response is a correlate of delayed hypersensitivity. 
Summary

Lymphocytes from four out of five children with Bruton-type agammaglobulinemia showed a specific in vitro response to candida antigen as measured morphologically and by incorporation of tritiated thymidine into DNA. This in vitro response correlated with the presence of a delayed hypersensitivity type skin reaction to the same antigen in the five patients with agammaglobulinemia, as well as with six positive and five negative controls. These results add further support to the proposal that the observations made using the lymphocyte culture model predict delayed hyper. sensitivity reactions.

\section{References and Notes}

1. BACH, F. and HrRschHorn, K. : Lymphocyte interaction: A potential histocompatibility test in vitro. Science 143: 813 (1964).

2. BAcH, F. and Voynow, N.K.: One-way stimulation in mixed leukocyte cultures. Science 154: 545 (1966).

3. Bach, F.H.; Meuwissen, H.J.; Albertini, R.J. and Good, R.A.: Gellular studies in agammaglobulinemia; in Diseases of immunologic deficiency (ed. Good, R.A.; Smith, R.T. and Miescher, P.B.) (National Foundation Press, 1967, in press).

4. Bain, B. and Lowenstein, L.: Genetic studies on the mixed leukocyte reaction. Science 145: 1315 (1964).

5. Buck, A. A. and Hasenclever, H.F.: Epidemiologic studies of skin reactions and serum agglutinins to Candida albicans in pregnant women. Amer.J. Hyg. 78: 232 (1963).

6. Cooperband, S.R.; Rosen, F.S.; Krbrick, S. and JANEWAy, C.A.: Gamma globulin synthesis by lymphocytes from normal and agammaglobulinemic individuals. J. clin. Invest. 45: 998 (1966).

7. Fellner, M.J.; Baer, R.L.; Ripps, C.S. and HirschHorn, K.: Response of lymphocytes to penicillin: Comparison with skin tests and circulating antibodies in man. Nature (Lond.) 216: 803 (1967).

8. Forbes, I. G. and Turner, K.J.: Synthesis of proteins by human lymphocytes in vitro. Aust. Ann. Med. 14: 311 (1965).

9. Fudenberg, H.H. and Hirschhorn, K.: Agammaglobulinemia: The fundamental defect. Science 145: 611 (1964).

10. Halpern, B.; Kx, N.T. and Amache, N.: Diagnosis of drug allergy in vitro with the lymphocyte transformation test. J.Allergy 40: 168 (1967).

11. Hersh, E. and Oppenheim, J.J.: Impaired in vitro lymphocyte transformation in Hodgkin's Disease. New Engl.J. Med. 273: 1006 (1965).

12. Hirschirorn, K.; BACH, F.; Kolodny, R.L.; Firschein, I.L. and Hasem, N.: Immune response and mitosis of human peripheral blood lymphocytes. Science 142: 1185 (1963).

13. Hirschhorn, K.; Schreibman, R.R.; Bach, F.H. and Siltzbach, L. E.: In vitro studies of lymphocytes from patients with sarcoidosis and lymphoproliferative diseases. Lancet 2: 842 (1964).

14. Hirschiorn, K.: The mitogenic effect of different substances on lymphocytes in tissue culture. Series haemat. 9: 26 (1965).

15. HirschHORN, K.: In histocompatibility testing. National Research Council Publication No. 1229 (ed. Russell, P.S. and Wrnn, H.J.), p.177 (National Academy of Science, 1965).

16. Ling, N.R. and Soothild, J.F.: Lymphocyte transformation. Brit. med.J. 2: 1460 (1964).

17. Mancini, G.; Vaerman, J.P.; Garbonara, A.O. and Heremans, J.F.: A single-radial-diffusion method for the immunological quantitation of proteins. Proceedings 11 th Colloquium, Protides of the Biological Fluids, p. 370 (Elsevier, Amsterdam 1964).

18. McFarland, W. and Heilman, D.H.: Comparison of lymphocyte transformation and intradermal reactions to tuberculin. Amer.Res.resp. Dis. 93: 742 (1966).

19. Mrlls, J. A.: The immunologic significance of antigen induced lymphocyte transformation in vitro. J. Immunol. 97: 239 (1966).

20. Oppenheim, J.J.; Wolstencroft, R. A. and Gell, P.G.H.: Delayed hypersensitivity in the guinea pig to a protein-hapten conjugate and its relationship to in vitro transformation of lymph node, spleen, thymus and peripheral blood lymphocytes. Immunology 12: 89 (1967).

21. Robbins, J.H.: Tissue culture studies of the human lymphocyte. Science 146: 1648 (1964).

22. Sell, S.; Row, D.S. and Gell, P.G.H.: Studies on rabbit lymphocytes in vitro. III. Protein, RNA and DNA synthesis by lymphocyte cultures after stimulation with phytohemagglutinin, with staphylococcal filtrate, with antiallotype serum and with heterologous antiserum to rabbit whole serum. J. exp. Med. 122: 823 (1965).

23. Shannon, D. G.; Johnson, G.; Rosen, F.S. and Austen, K.F.: Cellular reactivity to Candida albicans antigen. New Engl.J.Med. 275: 690 (1966).

24. Van Furth, R.; Schuit, H.R.E. and Hijmans, W.: The formation of immunoglobulins by human tissues in vitro. IV. Girculating lymphocytes in normal and pathological conditions. Immunology 11 : 29 (1966). 
25. Laboratoire Roger Bellon, Neuilly, France.

26. Hollister-Stier Laboratories, Downers Grove, Illinois.

27. New England Nuclear Corp., Boston, Massachusetts.

28. PHA-M; Difco Laboratories, Detroit, Michigan.

29. Hollister-Stier Laboratories, Downers Grove, Illinois.

30. The author thanks Dr. IRving Schulman and Dr. Sheldon Dray for reviewing this manuscript and gratefully acknowledges the technical assistance of
Miss Sharon Melvin and Mrs. Pamela Wendell. 31. Supported in part by a grant (AM-10318-01) from the National Institute of Arthritis and Metabolic Diseases and by a grant from the Psychiatric Training and Research Fund of the Illinois Department of Mental Health.

32. Requests for reprints should be addressed to: Samuel P.Gotoff, M.D., Department of Pediatrics, University of Illinois College of Medicine, Chicago, Ill. (USA). 